\title{
Microstructural features induced by spray forming of a ternary Pb-Sn-Sb alloy
}

\author{
V C SRIVASTAVA, ANISH UPADHYAYA and S N OJHA* \\ Department of Metallurgical Engineering, Banaras Hindu University, Varanasi 221 005, India
}

MS received 6 January 2000

\begin{abstract}
An alloy containing $\mathrm{Pb}-12 \% \mathrm{Sn}-12 \% \mathrm{Sb}$ with small addition of copper and arsenic was spray deposited employing two different atomization gas pressure and nozzle to substrate distances. The temperature of the spray-deposit was measured during deposition at a distance of 2 and $10 \mathrm{~mm}$ above the substrate-deposit interface. Thermal profile data indicated small variation in temperature with time during deposition stage whereas during post deposition stage an exponential decrease in temperature was recorded. Second phase particle size along the thickness of the deposit varied from 4 to $8 \mu \mathrm{m}$ compared to 70 to $80 \mu \mathrm{m}$ size of these particles in the as cast alloy. Maximum porosity occurred in the section of the deposit near the contact surface of the substrate and also in its peripheral regions. $X$-ray diffraction analysis exhibited the formation of additional $\mathrm{Cu}_{2} \mathrm{Sb}$ phase in the spray-deposit and $\mathrm{CuSn}$ and $\mathrm{Cu}_{3.3} \mathrm{Sb}$ phases in atomized powders compared to that of the as cast alloy. The microstructural evolution during spray deposition of this alloy is discussed.
\end{abstract}

Keywords. Spray forming; thermal profile; microstructure; second phase; porosity.

\section{Introduction}

Lead and tin based alloys are widely used as engineering materials in bush bearing applications. These alloys are currently produced by the conventional casting methods. A uniform distribution of a hard $\mathrm{SnSb}$ intermetallic compound in a ternary eutectic matrix provides wear resistance of the alloy. However, due to the slow cooling rate involved in the casting process, agglomeration of $\mathrm{SnSb}$ compound occurs in the casting due to its higher melting point and lower density (Forrester 1960). A small amount of copper is added in the melt to facilitate formation of yet another intermetallic compound $\mathrm{Cu}_{6} \mathrm{Sn}_{5}$ with fine needle like morphology with a melting point higher than that of $\mathrm{SnSb}$ compound. As a result, the flotation of $\mathrm{SnSb}$ compound with a cuboidal morphology is impeded by $\mathrm{Cu}_{6} \mathrm{Sn}_{5}$ phase. The control of size and size distribution of the second phase in these alloys has an added advantage in an improvement of their wear properties.

An effective microstructural control during spray forming of this alloy provides an exciting new opportunity in their processing. Several microstructural benefits of this processing methodology are by now well established. Rapid solidification effects inherent in spray deposition due to high heat exchange rate at the droplet-gas interface and also on the deposition surface ensures chemical and microstructural homogeneity of the resultant materials (Lavernia 1989; Ojha et al 1991; Ohja 1992). In addition,

*Author for correspondence a uniform dispersion of fine second phase particles provides their enhanced wear properties (Ojha et al 1992; Upadhyaya et al 1997). These features of spray formed alloys have been attributed to depend in a complex way on droplet dynamics and their thermal state on the deposition surface (Mathur et al 1989; Singh et al 1992; Grant and Cantor 1995). It has been suggested, based on measurement of thermal histories during spray deposition, that too low a solid fraction in the spray results in formation of an excessive liquid pool on the deposition surface. A high velocity gas jet causes splashing of the liquid and the formation of large size pores of the entrapped gases (Bewley and Cantor 1991). In this case, the microstructure of the preform resembles that of a typical cast structure. Alternatively, an excess solid fraction in the spray generates a preform with a large amount of porosity due to insufficient liquid phase available to provide bonding of particles during solidification of the spray-deposit (Lavernia et al 1992). Consequently, an optimum control of the process variables is greatly emphasized to derive the maximum benefits of spray deposition process.

In a previous investigation, the effect of atomization gas pressure and nozzle to substrate distance were optimized in spray deposition processing of a commercial lead based babbit alloy (Upadhyaya et al 1997). The disc shape preform exhibited a substantial reduction in porosity of the deposit. In the present work, the thermal history of the preform during spray deposition is evaluated. The microstructure of the deposit is analysed and compared with that of the atomized powders and as cast alloys. 


\section{Experimental}

\subsection{Spray deposition}

The details of spray forming set-up are described elsewhere (Ojha et al 1993). In brief, the process employs an annular convergent-divergent nozzle, with a throat area of $20.5 \mathrm{~mm}^{2}$ and an exit to throat area ratio of $3: 1$, for atomization of the melt. In this process, the gas interacts with the melt stream at the tip of a flow tube concentric to the gas flow channel to promote atomization of the melt. The resultant spray of droplets is deposited on a steel substrate in an environmental chamber connected to a cyclone to collect the over spray powders. A schematic illustration of the deposition process is shown in figure 1 .

The composition of alloy consisted of $\mathrm{Pb}-12 \% \mathrm{Sn}-12 \%$ $\mathrm{Sb}-1.5 \% \mathrm{Cu}$ with traces of arsenic (composition is given in wt\%). In each experiment $2.5 \mathrm{~kg}$ of the alloy was charged in a graphite bonded fireclay crucible. The melting was carried out in a resistance heating furnace under nitrogen gas atmosphere. The temperature of the melt was measured using a chromel-alumel thermocouple connec-

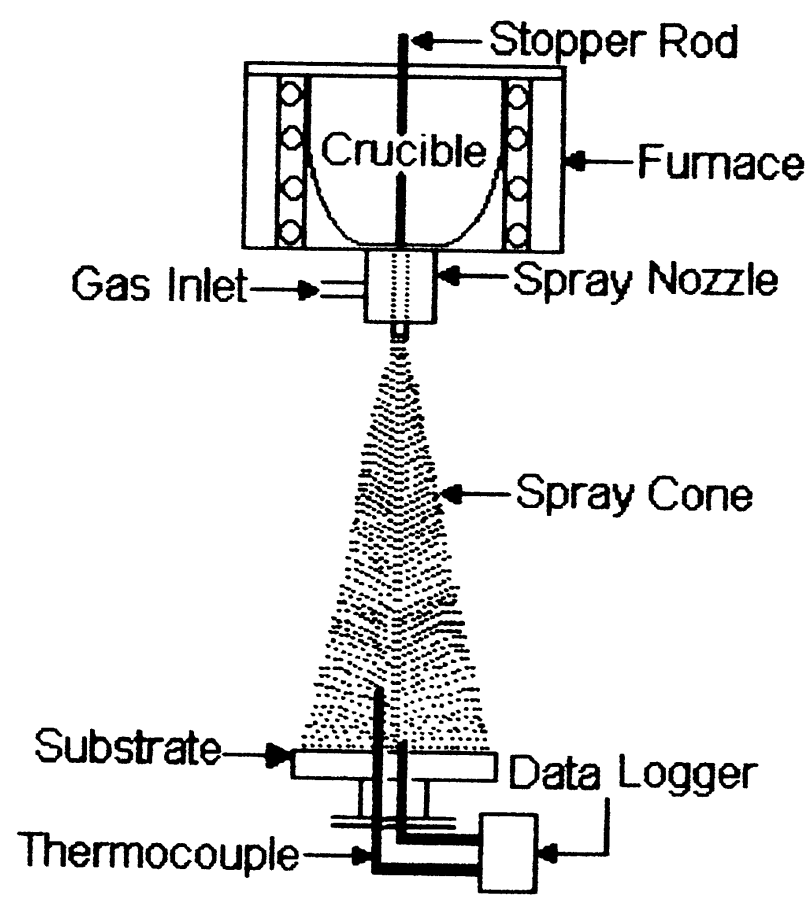

Figure 1. Schematic diagram illustrating spray deposition. ted to a temperature recorder. A melt superheat of $200^{\circ} \mathrm{C}$ was ensured to stop the premature freezing of the melt. The details of the process variables are listed in table 1 . The melt was atomized by nitrogen gas at an atomization gas pressure of $1.2 \mathrm{MPa}$ and nozzle to substrate distance of 0.35 meter. The thermal profile measurement was carried out during this experimental condition only. In another set of experiments the gas pressure was reduced to $1 \mathrm{MPa}$ and nozzle to substrate distance of 0.25 meter. The melt flow rate was obtained by the mass of the charge in the crucible and duration of atomization. The gas flow rate was measured using a gas flow meter.

\subsection{Measurement of thermal profile}

Two chromel-alumel thermocouples were inserted through a hole in the substrate. These were centred along the axis of the spray. The hot junctions of thermocouples were positioned at a distance of $2 \mathrm{~mm}$ and $10 \mathrm{~mm}$ above the surface of the substrate as shown in figure 1. Thermocouple wires were insulated in alumina seaths to avoid their contact with the metal substrate. The spray nozzle and substrate were leveled to align the thermocouples with the axis of the melt spray. The output of the thermocouples were recorded during and after spray deposition using a Data Acquisition System with a response time of one sec.

\subsection{Materials characterization}

Several samples from the centre and peripheral regions of the spray-deposit were prepared for the microstructural examination. These were polished by standard metallographic procedure and etched with a $5 \%$ Nital solution. The microstructural examination was carried out in a Metallux-3 optical microscope. The size distribution of the second phase particles was measured using a VIDS image analyser. X-ray diffraction study of the samples from the spray-deposit and over spray powder particles were carried out in a Rigaku X-ray Diffractometer using $\mathrm{CuK}_{\alpha}$ radiation.

\section{Results}

\subsection{Temperature profile of the spray-deposit}

The temperature profile of spray-deposit during and after deposition is shown in figure 2 . These were generated in

Table 1. Process variables employed during spray deposition.

\begin{tabular}{cccccc}
\hline Run & $\begin{array}{c}\text { Gas pressure } \\
(\mathrm{MPa})\end{array}$ & $\begin{array}{c}\text { Gas flow rate } \\
\left(\mathrm{gs}^{-1}\right)\end{array}$ & $\begin{array}{c}\text { Melt flow rate } \\
\left(\mathrm{gs}^{-1}\right)\end{array}$ & $\begin{array}{c}\text { Melt superheat } \\
\left({ }^{\circ} \mathrm{C}\right)\end{array}$ & $\begin{array}{c}\text { Deposition distance } \\
(\mathrm{m})\end{array}$ \\
\hline 1 & $1 \cdot 2$ & 30 & 120 & 200 & $0 \cdot 35$ \\
2 & $1 \cdot 0$ & 26 & 90 & 200 & $0 \cdot 25$ \\
\hline
\end{tabular}


the preform at a deposition distance of $0.35 \mathrm{~m}$ on a steel substrate employing a melt flow rate of $120 \mathrm{gs}^{-1}$ and gas flow rate of $30 \mathrm{gs}^{-1}$. Thermocouple marked as TC- 1 in the above figure was protruded to $2 \mathrm{~mm}$ above the substrate surface whereas that marked TC-2 recorded the temperature at $10 \mathrm{~mm}$ above the substrate. The temperature of the deposit $2 \mathrm{~mm}$ above the deposit-substrate interface is observed to rise rapidly after the start of the spray deposition to a temperature of $200^{\circ} \mathrm{C}$ and then decreased to $195^{\circ} \mathrm{C}$ and maintained nearly a constant temperature throughout the deposition process. The second thermocouple (TC-2) initially recorded a lower peak temperature which further increased to $206^{\circ} \mathrm{C}$ towards the end of the deposition cycle. After spray deposition both the thermocouples exhibited an exponential decrease in the temperature.

The above result indicates that the two thermocouples yield similar temperature profiles. The thermocouple junction positioned $2 \mathrm{~mm}$ above the substrate surface measures the temperature history of the spray-deposit at the initial stages of deposition. During spray deposition this temperature sharply increases and during post deposition cooling the temperature decreases exponentially with increasing time. Both the thermocouples protruding initially measures the temperature of droplets which land on the hot junction. These droplets do not experience cooling by the substrate and their temperature increase before they are embedded in the spray-deposit. The first thermocouple reaches this condition at an early stage. Subsequently, the thermocouple measures the thermal profile of the spray-deposit. When the thickness of the deposit increases, there is a small variation in temperature during spray deposition, whereas the post deposition temperature profile exhibits large temperature gradient across the deposit thickness.

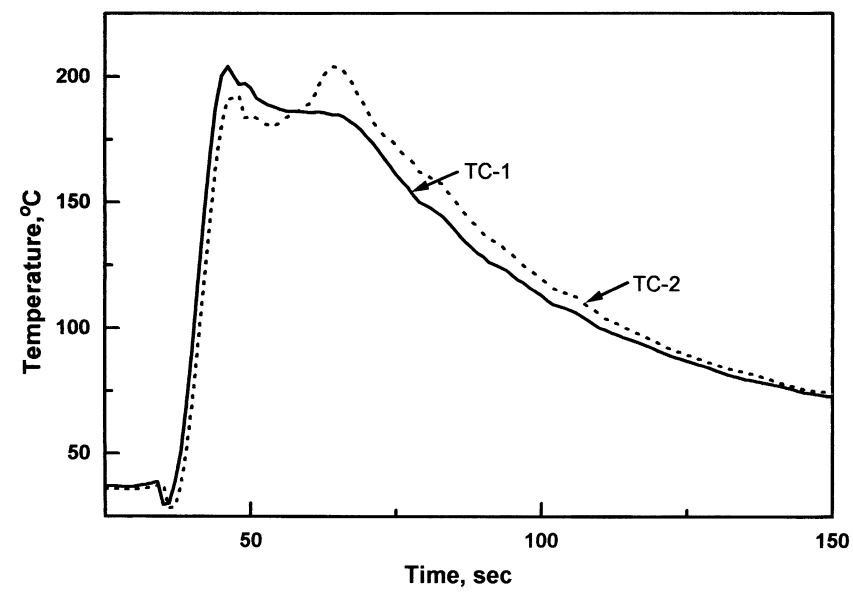

Figure 2. Temperature profile generated during spray deposition of $\mathrm{Pb}-\mathrm{Sn}-\mathrm{Sb}$ alloy.

\subsection{Phase identification}

The X-ray diffraction results of the spray formed alloy and that of the atomized powders showed several peaks as shown in figure 3. The diffraction peaks were sharp and distinct. These indicated that the alloys contained a large number of intermetallic phases. The scale of intensity for recording diffraction pattern of the as cast and spray formed alloy was $1.5 \mathrm{kcps}$ whereas the same was taken at $4 \mathrm{kcps}$ for the atomized powders. This suggests that the diffraction intensities obtained from powders are more intense because of large number of fine randomly oriented grains/particles present in powder particles.

The diffracting planes were indexed and it was found that the $d_{h k l}$ values for lead in case of powders was more than the actual value corresponding to pure lead. However, in the as cast alloy the two $d$-values were nearly equal. It suggests that rapid solidification rate to which the atomized powder is subjected, results in increased solid solubility of other elements in lead to form a metastable lead-rich solid solution phase. The cast alloy on the other hand is subjected to a long solidification time resulting in sufficient degree of solute rejection from the solidifying lead rich phase. The formation of additional new metastable phases $\beta^{\prime \prime}$ with $\mathrm{CuSn}$ composition and

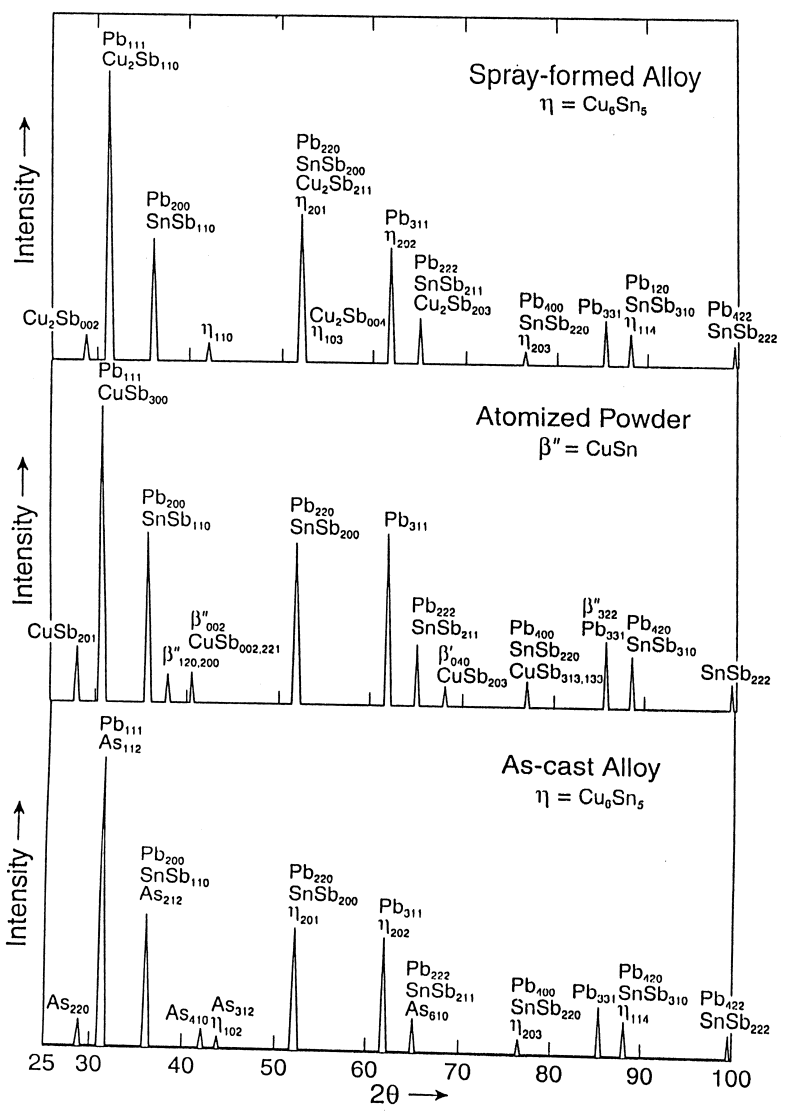

Figure 3. Comparison in X-ray diffraction patterns of spray formed, atomized powder particles and as cast alloy. 
$\mathrm{Cu}_{3.3} \mathrm{Sb}$ phase is revealed in the diffraction pattern of atomized powders. On the other hand, in diffraction pattern of the spray formed alloy $\mathrm{Cu}_{2} \mathrm{Sb}$ phase is noticed which does not exist in the as cast alloy. The cast alloy reveals diffraction peaks due to the presence of arsenic which is not present in spray deposited alloy and its atomized powders. This suggests that the segregation of arsenic in the cast alloy arises from its slow cooling rate. The results of X-ray diffraction studies showing more number of metastable phases in the spray formed alloy and also in gas atomized powders indicate that the melt is subjected to rapid solidification during spray forming of this alloy.

\subsection{Microstructural features}

Microstructural examination of the spray-deposit revealed ultrafine second phase particles and small size porosity near the substrate-deposit interface (figure 4a). The pore size varied from 2 to $10 \mu \mathrm{m}$. The amount of porosity considerably decreased with an increase in size of the second phase particles (figure $4 b$ ). The section from the top surface of the deposit again showed increased amount of porosity. A decrease in the atomization gas pressure and deposition distance both resulted in formation of large size porosity and coarse second phase particles in the deposit. The microstructure of the as cast alloy shown in figure 5 a exhibited uneven distribution of second phase particles in a coarse irregular eutectic matrix. The microstructural features of spray formed alloy showed considerable refinement in both the second phase particles and the constituents of the eutectic phases (figure $5 \mathrm{~b}$ ). The bulk of the second phase particles, identified as $\mathrm{SnSb}$ intermetallic compound in X-ray diffraction analysis showed characteristic faceted growth morphology. The histogram of the second phase particle size distribution of both the spray-deposit and that of as cast alloy is presented in figures 6 and 7. It is worthwhile to note that the size of the second phase particles in spray-deposit varies from 1 to $10 \mu \mathrm{m}$ with maximum number of particles in close size range of 4 to $8 \mu \mathrm{m}$. In contrast the size of the second phase particles in the as cast alloy varies from 30 to $100 \mu \mathrm{m}$ with frequency of occurrence of maximum particles in 70 to $80 \mu \mathrm{m}$ size range. This indicates an order of magnitude refinement in their size in the spraydeposit compared to that of the as cast alloy.

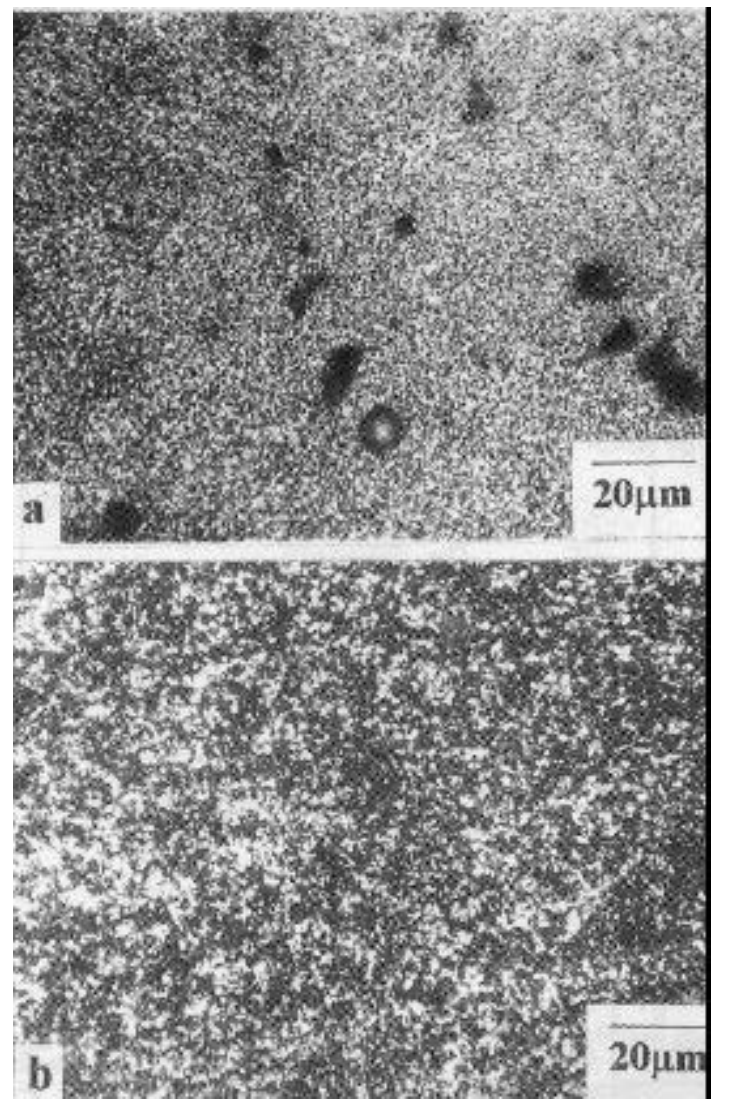

Figure 4. Microstructure of spray-deposit near the substrate showing a. porosity and $\mathbf{b}$. fine scale microstructure of second phase particles.

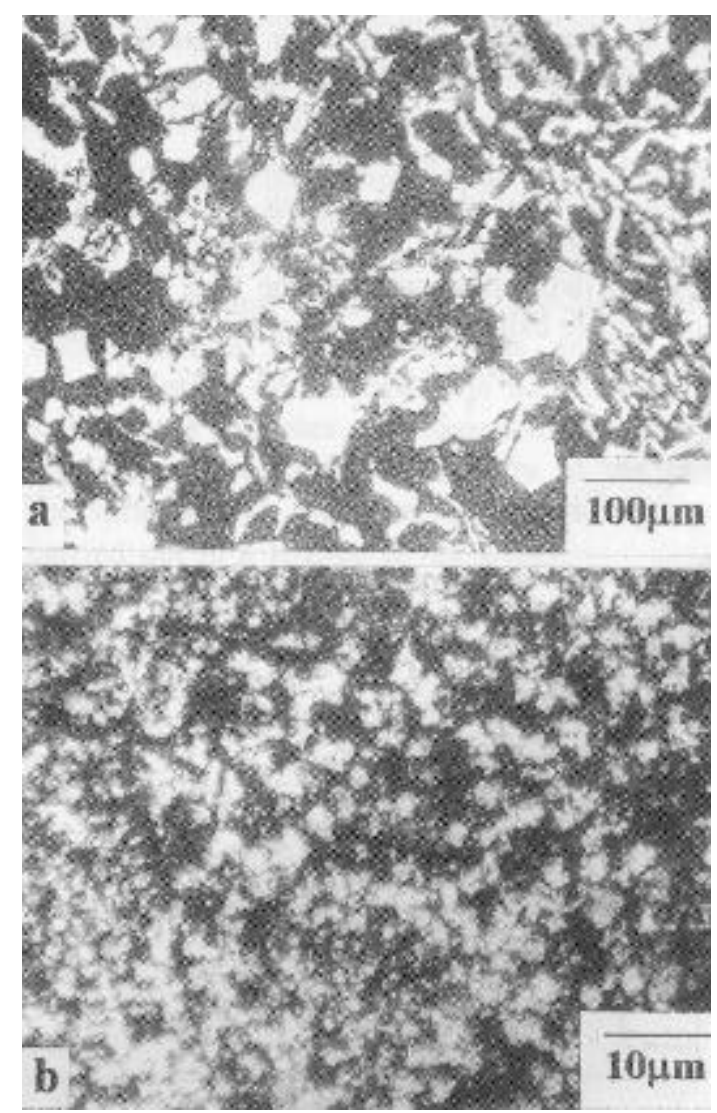

Figure 5. Microstructure of the alloy showing a. coarse particles in the as cast alloy and $\mathbf{b}$. fine second phase particles in spray-deposit. 


\section{Discussion}

Melt atomization in spray forming process generates a wide size range of droplets in the spray. The cooling rate of droplets vary with their size and approaches well within rapid solidification regime (Srivastava et al 1998). Observation of metastable phases in the diffraction pattern of atomized powder particles substantiate high cooling rate achievable during solidification of droplets. During time of deposition this effect is partially retained in the microstructure of the spray-deposit. The microstructural refinement in second phase particle size is achieved through a large number of solid particles collected in the liquid on the deposition surface. In a recent investigation, $\mathrm{Xu}$ and Lavernia (1999) provided evidence to show that these particles act as nucleation site for further crystallization of the melt. An alternative source of nucleation sites arises from semi-solid droplet and debris particles of dendrite fragments. Similar observations were also made by Bewley and Cantor (1990) based on measurement of the particle size distribution in gas atomized $\mathrm{Sn}-\mathrm{Pb}$ sprays. These investigators suggested that since the solid grows into the liquid from these particles prior particle boundaries are not observed in the final microstructure. This condition is governed by the heat influx on the depositing spray. However, when the heat extraction rate is high during early stages of the spray deposition on the solid substrate the initial solidification structure of the atomized droplets are fully retained in the microstructure of the deposit due to insufficient time available for their remelting or coarsening. Such features can be observed in the microstructure of the deposit near the contact surface of the substrate (figure $4 \mathrm{a}$ ). In order to achieve microstructural homogeneity thermal conditions must be controlled so that heat influx is balanced by the heat extraction rate. This condition arises with increasing thickness of the spray-deposit with time of deposition leading to a relatively low heat extraction rate. The con-

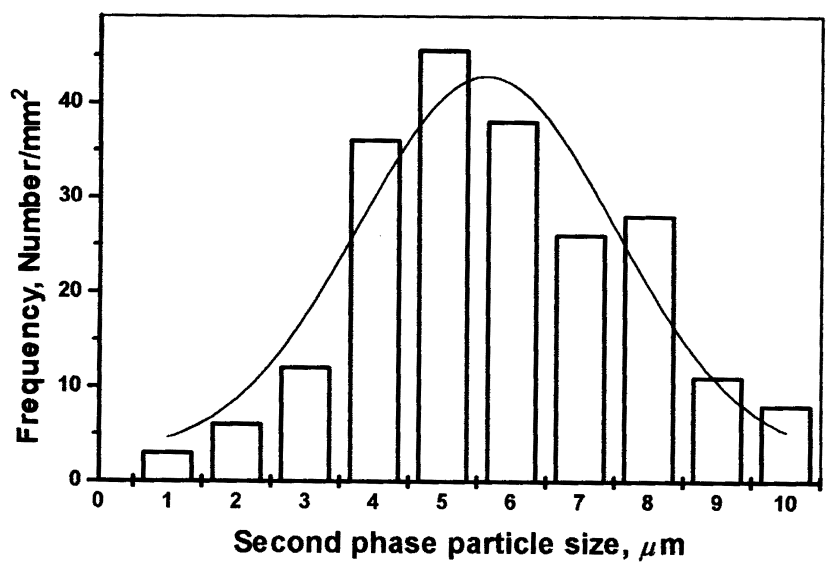

Figure 6. Histogram showing distribution of second phase particles in spray-deposit of $\mathrm{Pb}-\mathrm{Sn}-\mathrm{Sb}$ alloy. trol of process variables results in considerable influence on the size and size distribution of intermetallic phases of this alloy. In addition the second phase particles size vary along the through thickness direction of the deposit. Similar variation in the microstructure of the spraydeposit, produced a low atomization gas pressure and increased nozzle to substrate distances was reported by Upadhyaya et al (1997). However, with an increase in both the gas pressure and nozzle to substrate distance, the second phase particles were observed to be relatively small and uniformly distributed along the thickness of the deposit.

The measurement of thermal profile data of the spraydeposit provides an insight into the observed microstructural variation. The cooling rate experienced by the spray-deposit is governed by the Nusselt number defined as

$$
\mathrm{Nu}=h x / k,
$$

where $h$ is the heat transfer coefficient at the substratedeposit interface, $k$ the thermal conductivity of the material and $x$ the thickness of deposit. Variation in thickness of the deposit during deposition process results in a wide range of the Nusselt number applicable in spray forming process. At early stages of deposition, the spray-deposit thickness is extremely small, little thermal resistance is provided by the deposit thickness to the overall heat transfer rate. The heat transfer from the deposit occurs by the Newtonian cooling condition as $\mathrm{Nu} \ll 1$ since thickness of the deposit is extremely small at this stage. However, as the thickness of the deposit increases with time of deposition, thermal resistance by the spray-deposit increases. Subsequent stages of deposition process, the heat transfer from the spray-deposit takes place under ideal cooling condition as $\mathrm{Nu} \gg 1$ with a substantial increase in thickness of the spray-deposit. When spray deposition rate is constant and lower than the achievable rate of solidification, the material can solidify faster than

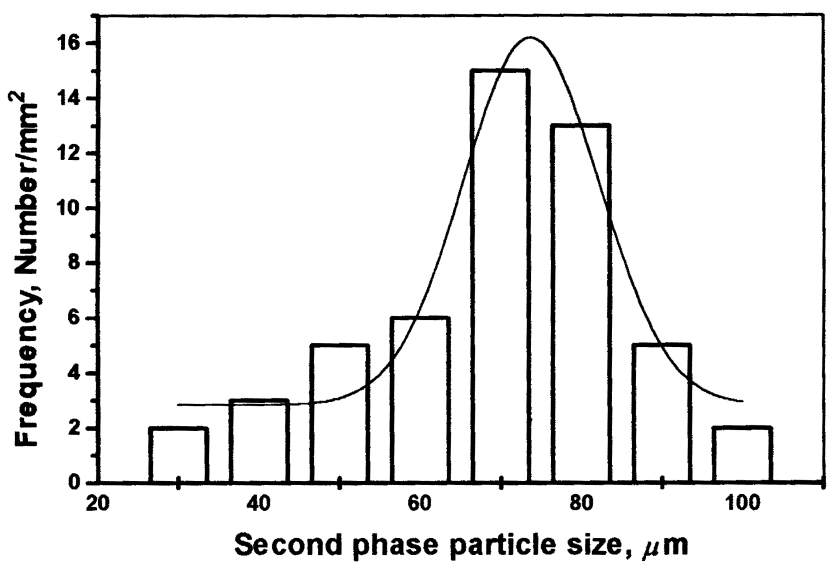

Figure 7. Histogram showing second phase particle size distribution in the as cast alloy. 
it is being deposited. This condition of the spray deposition would lead to the formation of the agglomerate of splats with distinct spray boundaries in the deposit as reported by Fuxiao et al (1996). However, when ideal cooling condition prevails the solidification rate decreases with increasing time. At this critical distance the deposit solidify at the same rate as the rate of deposition. Bewley and Cantor (1991) consider this situation crucial for the spray deposition as the rate of input of the heat flux is balanced by the heat removal rate. In this condition a liquid layer is developed on the deposition surface leading to formation of a uniform microstructure and reduction in porosity of the deposit. Beyond this critical thickness of the deposit, the arrival of the heat flux on the deposition surface becomes more than the heat extraction and solidification rate. This results in a build up of an excessive molten pool on the deposition surface and the microstructure of the spray-deposit deviates from that of the optimum spray deposition condition. The measurement of thermal profile indicates that the cooling rate in the present deposition condition is not Newtonian as there are considerable temperature gradients across the deposit thickness. This effect is expected to result in a variation in scale of the microstructure and porosity of the spray-deposit.

\section{Conclusions}

(I) Thermal profiles of the spray-deposit of a $\mathrm{Pb}-\mathrm{Sn}-\mathrm{Sb}$ alloy reveal small variation in temperature at 2 and $10 \mathrm{~mm}$ from the substrate-deposit interface during time of deposition. An exponential decrease in temperature occurs during the post deposition stage. Temperature gradient in the deposit indicates increasing resistance to heat transfer with growth in thickness of the spray-deposit.

(II) Microstructure of the spray-deposit exhibits considerable refinement in second phase particle size varying from 4 to $8 \mu \mathrm{m}$ compared to the second phase particle size of 70 to $80 \mu \mathrm{m}$ in the as cast alloy. The spray-deposit near the substrate shows small size porosity which is eliminated with increasing thickness of the deposit.
(III) X-ray diffraction analysis shows formation of an additional $\mathrm{Cu}_{2} \mathrm{Sb}$ metastable phase in the spray-deposit and $\mathrm{CuSn}$ and $\mathrm{Cu}_{3.3} \mathrm{Sb}$ phases in the atomized powders of this alloy. These phases do not exist in diffraction pattern of the as cast alloy. This result indicates that rapid solidification effects are inherent in spray deposition processing.

\section{Acknowledgement}

The authors acknowledge the financial assistance received from the Aeronautics Research and Development Board, Ministry of Defence, Government of India.

\section{References}

Bewley B P and Cantor B 1990 Met. Trans. B21 899

Bewley B P and Cantor B 1991 J. Mater. Res. 61433

Forrester P G 1960 Metall. Rev. 5507

Fuxiao Y, Dwarakadasa E S and Ranganathan S 1996 Proceedings international conference on spray forming (ICSF3) (Cardiff, UK: Paul Ellerington Printers) p. 313

Grant P S and Cantor B 1995 Acta Metall. Mater. 43913

Lavernia E J 1989 Int. J. Rapid Solidification 551

Lavernia E J, Ayers J D and Srivatsen T S 1992 Int. Mater. Rev. 371

Mathur P, Apelian D and Lawley A 1989 Acta Metall. 37429

Ojha S N 1992 Bull. Mater. Sci. 15527

Ojha S N, Jha J N and Singh S N 1991 Scr. Metall. Mater. 25 443

Ojha S N, Pandey O P, Tripathi B, Kumar M and Ramchandra C 1992 Mater. Trans. JIM 33519

Ojha S N, Tripathi A K and Singh S N 1993 Powder Met. Int. 2565

Singh S N, Mishra N S and Ojha S N 1992 Steel Res. 6312

Srivastava A K, Ojha S N and Ranganathan S 1998 Met. Mater. Trans. A29 2205

Upadhyaya A, Mishra N S and Ojha S N 1997 J. Mater. Sci. 32 3227

Xu Q and Lavernia E J 1999 Scr. Metall. Mater. 41535 